\title{
Optimization of parameters on material removal rate in micro-WEDG process
}

\author{
PR. Periyanan ${ }^{*}$, U. Natarajan ${ }^{2}$, A. Elango ${ }^{2}$ \\ ${ }^{1 *}$ Department of Mechanical Engineering, Shanmuganathan Engineering College, INDIA \\ ${ }^{2}$ Department of Mechanical Engineering, A.C.College of Engineering \& Technology, INDIA \\ *Corresponding Author: e-mail: prp_me@yahoo.co.in
}

\begin{abstract}
The micro-electrical discharge machining (micro-EDM) process has proved to be an appropriate nonconventional machining method for manufacturing accurate and complex three dimensional structural micro-parts and micro-tools which are difficult to be produced by conventional machining processes. The accuracy and the repeatability of the $\mu$ EDM process are still highly dependent on the $\mu \mathrm{WEDG}$ process. In this work, an orthogonal array, signal to noise $(\mathrm{S} / \mathrm{N})$ ratio and Pareto analysis of variance (ANOVA) are employed to analyze the effect of the micro-WEDG parameters such as feed rate, capacitance and voltage on MRR. This paper focuses on the Taguchi technique for the optimization in micro-WEDG process to achieve maximum metal removal rate (MRR) considering the feed rate, capacitance and voltage as the cutting parameters. Based on the experimental result and analysis it is concluded that medium feed rate, high value of capacitance and voltage such combination of optimized parameters gives high value of MRR $(0.39 \mathrm{mg} / \mathrm{min})$. The experimental result shows that the most influential parameter on the MRR is feed rate, capacitance and voltage. Also from the verification experiment it is concluded that Taguchi technique is suitable to solve the above said problem.
\end{abstract}

Keywords: Taguchi method of DOE, optimization, micro-WEDG, MRR, Pareto ANOVA

DOI: http://dx.doi.org/10.4314/ijest.v3i9.5

\section{Introduction}

Demand for micromachining has been on the rise in recent years owing to increasing miniaturization (Jain et al., 2011). Miniaturized components and products have been in strong demand because of their unique advantages such as less space requirement, less energy and material consumption, easiness in carrying, and/or handling and can be cheaper (Jain et al., 2011). In the twenty first century biological, medical and environmental technologies will become new frontiers to maintain and improve our lives. These technologies will be supported and improved by such advanced engineering techniques as fine materials, microfabrication and new concepts of design and control methods. Micro Electrode Discharge Machining ( $\mu$ EDM) is an emerging technology in the field of micro-machining to fabricate the micro-parts and micro tools. During the $\mu$ EDM process the volumetric wear, the ratio between electrode and work piece wear, is relatively high and cannot be considered as negligible (Bigot et al., 2005). Thus, to manufacture micro-parts there is often need to compensate the wear by replicating electrodes. To address this requirement, a technique for on-the machine electrode generation was developed, that utilized a technology called micro-Wire Electrode Discharge Grinding (Mazuzawa et al., 1985). The accuracy and repeatability of the $\mu$ EDM process is still highly dependent on the $\mu$ WEDG process. The electrode generation and regeneration is considered a key enabling technology for improving the performance of the $\mu$ EDM process (Masuzawa, 2001).

Many researchers have attempted to fabricate functional micro-parts and components using micro electric discharge machining (Bigot et al., 2006, Kunieda et al., 2006, Wong et al., 2003). Since this non contact process requires little or almost no force between the tool electrode and work piece. But it is mandatory that every discharge location is uniformly distributed over the working surface in order to reduce the tool wear and surface roughness of the work piece (Yu et al., 1998). Moreover, the work 
piece material should be electrically conductive in micro-EDM process. In recent years, a number of researchers have investigated the implementation of $\mu$ WEDG process with $\mu E D M$. Piltz et al. (2006) studied the effect of three different approaches for producing cylindrical components through the process of EDM in particular, the process behavior in terms of pulse stability, hydrodynamic behavior if dielectrics and machine dependent gap and feed control were investigated. Mehfuz et al. (2008) investigated the influence of three micro-electro discharge milling process parameters, which were feed rate, capacitance and voltage. The response variables were average surface roughness (Ra), maximum peak to valley roughness height (Ry), tool wear ratio (TWR) and material removal rate (MRR). Statistical models of these output responses were developed using three level full factorial designs of experiments. The developed models were used for multiple response optimizations by desirability function approach to obtain minimum Ra, Ry, TWR and maximum MRR. The WEDG process relies on an electrical discharge between a travelling wire and a rotating electrode.

Extensive research has been carried out on WEDG when implemented with micro-EDM. In particular it is a proven method for on the machine manufacture of micro electrodes for EDM drilling and milling. Wang et al. (2005) presented the influence of micro-end milling cutting conditions on roughness of a surface machined using a miniaturized machine tool. They used statistical methods such as ANOVA and RSM for finding out the optimal values of milling parameters also the interaction effect of parameters to surface roughness was discussed and the mathematical model for micro end milling was established. Based on the statistical method they conclude the value of surface roughness increased linearly with increase of tool diameter and spindle speed: feed rate played an important role when other parameters are constant. The stiffness of cutter influences the surface roughness much more than feed rate because of the magnitude of parameters. It is shown that stiffness is the most important factors in micro end milling. Periyanan et al. (2011) studied the effect of parameters on surface roughness in micro-WEDG process. Based on their experimental result they concluded that low feed rate, capacitance and voltage such combination of optimized parameters gives low value of surface roughness.

Qu et al. (2002) derived a mathematical model for the material removal rate of a cylindrical wire EDM process. Also they investigated through a mathematical model the surface integrity and roundness of cylindrical WEDM parts using brass and carbide work material. They found through the model a good estimate of the surface finish and roundness of cylindrical WEDM parts. Chris et al. (2006) provide an overview of several approaches to micro machining by mechanical and electro-discharge method of metal removal. Each of these mechanical machining methods can be combined with EDM to achieve a customizable surface finish and further accuracy. Lee et.al. (2004) conducted a series of experiments in order to begin to characterize the range of attainable surface roughness values for the micro end milling process. A $229 \mu \mathrm{m}$ diameter end mill was used to cut the slots into aluminum (6061) samples. The machining factors studied were chip load, cutting speed and depth of cut. Further experiments were performed allowing the generation of a second order relationship between surface roughness and chip load. The second order model generated, which includes the effect of chip load, cutting speed, and the interaction between the two, predicts surface roughness reasonably well. Natarajan et al, (2011) conducted the experiment for the multiple response optimization in micro end milling operation to achieve maximum metal removal rate (MRR) and minimum surface roughness (Ra). In that work, second order quadratic models were developed for MRR and Ra, considering the spindle speed, feed rate and depth of cut as the cutting parameters using central composite design. The developed models were used for multiple response optimizations by desirability function approach to determine the optimum machining parameters.

Bissacco et al. (2010) presented an investigation on wear and material removal in micro-EDM milling for selected process parameter combinations typical of rough and finish machining of micro-features in steel. Based on discharge counting and volume measurements, electrode wear per discharge and material removal per discharge were measured for several energy levels. Lithography techniques like X-ray lithography, Laser beam Lithography, Electron beam Lithography can be used to fabricate micro-structures on silicon substrate. However, there are some limitations in these methods due to its quasi-3D structure, its low aspect ratio and restricted work-piece material. LIGA process and focused ion beam machining processes can be employed to achieve this high respect ratio. But these processes are not affordable and sophisticated (Matsui et al, 2001, Okuyama et al, 1998, $\mathrm{Lu}$ and Yoneyama, 1999) have investigated the cutting force in micro-lathe using a three dimensional force sensor. In their experimental work, a work-piece of $0.3 \mathrm{~mm}$ in diameter is clamped and cut to a minimum of $10 \mu \mathrm{m}$ in diameter with a rotational speed upto $15,000 \mathrm{rpm}$. The most serious problem in this micro-turning is the cutting force which tends to bend the work-piece. The step size, for which the shaft will not deflect plastically, was determined using material strength equations. A hybrid machining process of micro-turning and micro-EDM (Masazuwa., 1985; Rahman et al., 2007) has been attempted in order to minimize inaccuracies due to clamping and damage during transfer of electrodes.

Popov et al. (2010) attempted a cost effective and reliable method for setting up the work co-ordinate system for micro-milling operations employing an online tool-work piece voltage monitoring system and the viability of the method was verified in a series of experiments conducted on an ultra-precision micro-milling machining centre. The various models of cutting force, surface roughness, tool wear etc., developed for conventional machining processes cannot be applied to the micro-machining processes. It is due to the reason that the resistance force (viscous force) dominates the inertia (motive) force for the miniature components. It is well known that the Reynolds number is the ratio of inertia force to the viscous force. For the micro-size components, the Reynolds number is less than unity, because of the size effect (Fujimasa, 1996). Hence, when the chip thickness is very low, the rubbing and burnishing actions will lead to the elastic-plastic deformation, thereby increasing the cutting force and power consumption. Presently, micro-end milling is widely used for machining free form curves. Bao and Tansel (2000) developed 
cutting force and tool wear models for micro-end milling. Son et al. (2005) found that a continuous chip was produced with the best surface finish when the chip thickness is minimum and further observed that feed is having influence for the surface roughness of the work-piece. To et al. (1997) conducted diamond turning of single crystal aluminium rods with crystallographic axes $\langle 100>,<110\rangle$ and $\left\langle 111>\right.$ using a diamond tool with a $0^{\circ}$ rake angle and $5^{\circ}$ clearance angle. They observed that the best surface finish was obtained in machining crystals with the $<100>$ planes as the cutting planes, whereas the $<110>$ planes would result in the highest surface roughness due to the highest cutting forces and large magnitudes of force variations. The authors claimed that the surface roughness was substantially influenced by the crystallographic orientation, but not significantly affected by the depth of cut over the range used in these experiments. Prakash et al. (2001) found that for the coated micro-end mill, the flank wear at the end of the cutting edge is the highest and that the feed rate and cutting speed have more significant influence over micro-cutting tool than axial depth of cut. Weinert and Petzoldt (2004) investigated the influence of tool size on the tool wear using SEM. Rahman et al. (2001) found that for small depth of cut $(0.15 \mathrm{~mm})$, the tool wear rate was higher than large depth of cut (0.25), in micro-milling of copper.

Literature review reveals that the researchers have carried out most of the work on micro-machining processes developments, monitoring and control but very limited work has been reported on optimization of process parameters. This experimental work investigates the influence of the various combinations of process parameters such as feed rate, capacitance and voltage in micro WEDG process, in an attempt to optimize the MRR when using the Taguchi technique and Pareto ANOVA method.

\section{Taguchi technique}

The Taguchi technique involves reducing the variation in a process through robust design of experiments (Periyanan et al., 2011; Park, 1996; Uanl and Dean, 1991; Phadke, 1989). The overall objective of the method is to produce high quality product at low cost to the manufacturer (Periyanan et al., 2011; Park, 1996; Uanl and Dean, 1991; Phadke, 1989). The Taguchi method was developed by Dr. Genichi Taguchi of Japan who maintained that variation. Taguchi developed a method for designing experiments to investigate how different parameters affect the mean and variance of a process performance characteristic that defines how well the process is functioning. The experimental design proposed by Taguchi involves using orthogonal arrays to organize the parameters affecting the process and the levels at which they should be varies. Instead of having to test all possible combinations like the factorial design, the Taguchi method tests pairs of combinations. This allows for the collection of the necessary data to determine which factors most affect product quality with a minimum amount of experimentation, thus saving time and resources. The Taguchi method is best used when there are an intermediate number of variables ( 3 to 50), few interactions between variables, and when only a few variables contribute significantly. The arrays are selected by the number of parameters (variables) and the number of levels (states). Analysis of variance on the collected data from the Taguchi design of experiments can be used to select new parameter values to optimize the performance characteristic. The data from the arrays can be analyzed by plotting the data and performing a visual analysis. Taguchi's parameter design is an important tool for robust design. It offers a single and systematic technique to optimize the design performance, quality and cost. Two major tools used in robust design are (Park, 1996; Uanl and Dean, 1991; Phadke, 1989).

a. Signal to noise ratio(S/N), which measures quality with emphasis on variation and

b. Orthogonal arrays, which accommodate many design factors simultaneously.

When a critical quality characteristics deviates from the target value it causes a loss. Continuously pursuing variable reduction from the target value in critical quality characteristics is the key to achieve high quality and reduce cost.

The general steps involved in the Taguchi technique are as follows:

1. Define the process objective, or more specifically, a target value for a performance measure of the process. The target of a process may also be a minimum or maximum. The deviation in the performance characteristic from the target value is used to define the loss function for the process.

2. Determine the design parameters affecting the process. Parameters are variables within the process that affect the performance measure can be easily controlled.

3. Create orthogonal arrays for the parameter design indicating the number of and conditions for each experiment. The selection of orthogonal arrays is based on the number of parameters and the levels of variation for each parameter.

4. Conduct the experiments indicated in the completed array to collect data on the effect on the performance measure.

5. Complete data analysis to determine the effect of the different parameters on the performance measure.

In Taguchi method, signal to-noise $(\mathrm{S} / \mathrm{N})$ is used to represent a response or quality characteristic and the largest $\mathrm{S} / \mathrm{N}$ ratio is required. There are usually three types of quality characteristics, i.e. target-the-best, larger-the-better and smaller-the better.

$$
\begin{aligned}
& \text { 1. Target-the-best: } \quad \mathrm{S} / \mathrm{N}=10 \log \frac{y}{s^{2} y} \\
& \text { 2. Larger-the-better: } \quad \mathrm{S} / \mathrm{N}=-10 \log \frac{1}{n}\left(\sum \frac{1}{y^{2}}\right)
\end{aligned}
$$


3. Smaller-the-better: $\quad \mathrm{S} / \mathrm{N}=-10 \log \frac{1}{n} \sum y^{2}$

where, $\mathrm{y}$ is the measured data, $\bar{y}$ is the average of measured data, $s^{2} y$ is the variance of $\mathrm{y}$ and $\mathrm{n}$ is the number of samples. For each type of the characteristics, with the above $\mathrm{S} / \mathrm{N}$ ratio transformation, the higher the $\mathrm{S} / \mathrm{N}$ ratio the better is the result.

\section{Experimental procedure}

The experimental works were carried out in a multipurpose micro-machine tool (DT 110, MIKROTOOLS) as shown in Figure (1) available in Central Manufacturing Technology Institute (CMTI), Bangalore, India. This machine can perform multiple machining processes such as micro-turning, micro-milling, micro-EDM, micro-ECM, micro-EDG and micro-wire EDM. In this research work, the micro-WEDG set up as shown in Figure (2c) was used. The tungsten electrode was hold by Rego-Fix microbore collet \& Rego-Fix clamping nut. (Shown in Figure 2a \& Figure 2b.) The Figure (2d) shows the attachment of micro-WEDG process. In this experiment with three factors at three levels each, the fractional factorial design used is a standard $\mathrm{L}_{27}\left(3^{13}\right)$ orthogonal array. This orthogonal array is chosen due to its capability to check the interactions among the factors. Each row of the matrix represents one trial. However, the sequence in which these trials are carried out is randomized. The three levels of each factor are represented by a ' 0 ' or a ' 1 ' or a ' 2 ' in the matrix. The factors and levels are assigned as in Table 1 . Factors $A, B$, and $C$ are arranged in columns 2,5 and 6 , respectively, in the standard $\mathrm{L}_{27}\left(3^{13}\right)$ orthogonal array as shown in Table 2 . The Feed rate $(A)$, Capacitance $(B)$ and Voltage $(C)$ are considered as input machining parameters. The levels of parameters that affect the performance of the micro-WEDG process are identified based on experience, discussion made with expert, survey of literature and preliminary experimentation performed by authors by considering more number of variables. Through the above observation the levels of parameters, which vigorously affect MRR was selected. Material removal rate which indicates processing time of the work piece is important factor that greatly influences production rate and cost. It is necessary to study the material removal rate in micro-WEDG process. Because of these, MRR is taken as output response. The responses of MRR were measured for the various sets of experimental data as shown in Table 3. MRR is the amount of work-piece material removed per unit time which can be measured by electric balance.

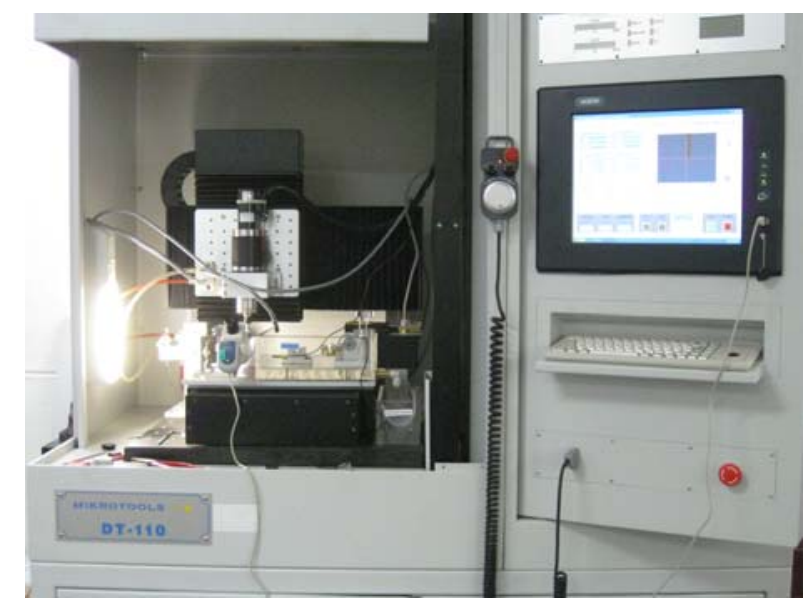

Figure 1. Multipurpose micro-machine tool 


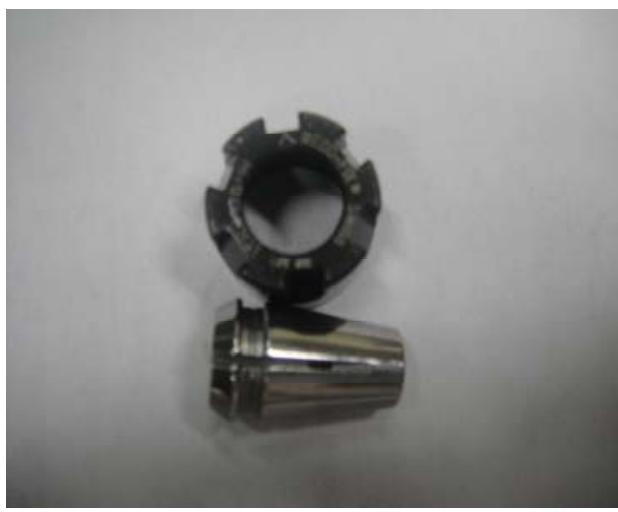

Figure 2.a. Rego-Fix microbore collet \& chuck

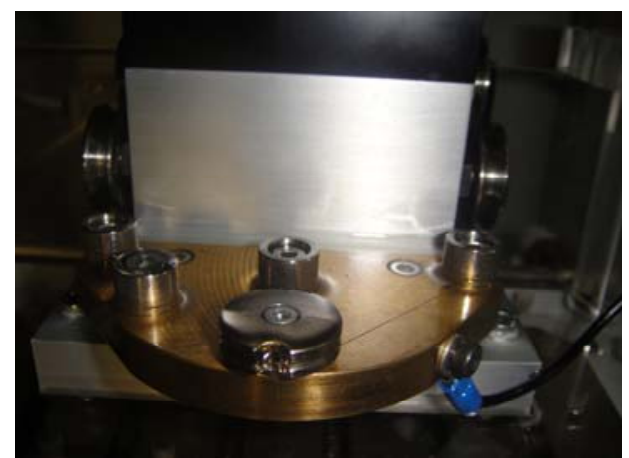

Figure 2c. WEDG device mounted on work table (Different views)

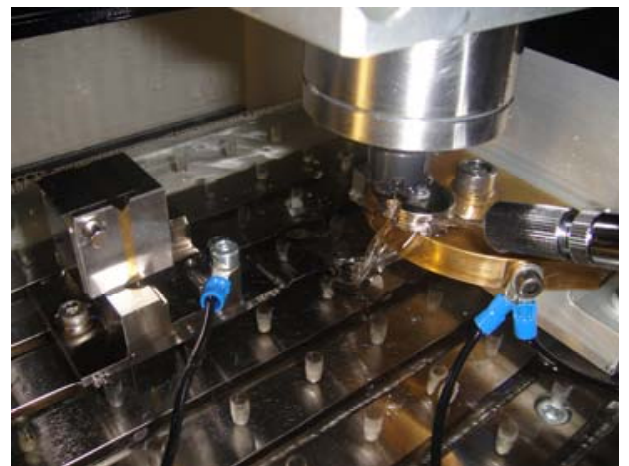

Figure 2d. Micro-WEDG process (Different views)

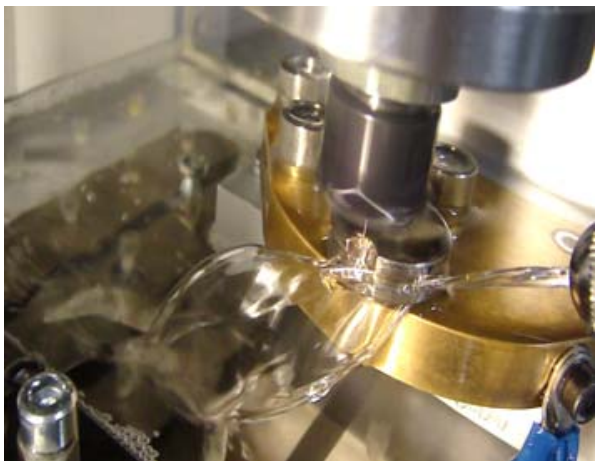

Figure 2. Experimental set up

Table 1. Selected machining parameter

\begin{tabular}{|l|l|l|l|}
\hline \multirow{2}{*}{ Factors } & \multicolumn{3}{|c|}{ Levels } \\
\cline { 2 - 4 } A:Feed rate $(\mu \mathrm{m} / \mathrm{sec})$ & Low $(0)$ & Medium $(1)$ & High $(2)$ \\
B:Capacitance $(\mathrm{nF})$ & 2 & 1.00 & 6 \\
C:Voltage $(\mathrm{V})$ & 0.10 & 100 & 10.00 \\
\hline \multicolumn{3}{|c|}{ Fixed parameters } \\
\hline Spindle speed $=200 \mathrm{rpm}$ & Threshold value $=30$ \\
Work material- tungsten (diameter $=300 \mu \mathrm{m})$ & Wire speed $=81 \mathrm{rev} / \mathrm{hr}$ \\
Tool material- Brass wire $($ diameter $=200 \mu \mathrm{m})$ & Wire tension $=50 \%$ \\
Dielectric fluid - synthetic oil & Polarity- work piece material $+\mathrm{ve}$ \\
\hline
\end{tabular}




\section{Experimental results and Analysis}

In order to assess the effect of each machining parameter on the micro-WEDG process, the Taguchi technique was used. This technique is type of statistical technique called Design of Experiments (DOE) that makes it possible to analyses the effect of more than one factor at the same time while reducing the number of experiments. Thus using the Taguchi approach, the design of experiments and analysis of results can be done with less effort and expenses. Hence this technique considerably reduces the number of experiments. One important step in the Taguchi technique is the identification of the control factors and of their values considered for investigation. The main objective of this experimental work is to optimize the micro-WEDG parameters to achieve the high value of MRR, the higher the better characteristics is used. The Table 2 shows the actual value for MRR along with their computed $\mathrm{S} / \mathrm{N}$ ratio. The Table 4 shows the response table for average $\mathrm{S} / \mathrm{N}$ ratio for surface roughness factors and significant interaction. The graphical representations of these data are as shown in Figure 3. Taguchi recommends analyzing the mean and $\mathrm{S} / \mathrm{N}$ ratio using conceptual approach that involves graphing the effects and visually identifying the factors that appear to be significant, without using ANOVA, because of these the analysis is simple. From the graphical representation of the factors and their interaction results shows that the capacitance and interaction between feed rate and voltage are more significant. Also from the graphs, we conclude that the feed rate, capacitance and voltage is more significant. The high value of MRR was obtained when the capacitance is higher in its range. But the interaction AXC is significant, the two ways table AXC is used (Park, 1996) to select their levels as calculated and the values are as shown in Table 5. Based on the results of two way table AXC, it is concluded that the optimum combination of that factor is $A_{1} C_{2}$. Therefore the optimal combination to get the high value of MRR is $A_{1} B_{2} C_{2}$ within the tested range of experiment.

Table 2. Orthogonal array for $\mathrm{L}_{27}\left(3^{13}\right)$ Taguchi design.

\begin{tabular}{|l|l|l|l|l|l|l|l|l|l|l|l|l|l|}
\hline Column & $\mathbf{B X C}$ & $\mathbf{A}$ & - & - & $\mathbf{B}$ & $\mathbf{C}$ & $\mathbf{B X C}$ & $\mathbf{A X B}$ & $\mathbf{A X C}$ & - & $\mathbf{A X B}$ & $\mathbf{A X C}$ & - \\
Trial & $\mathbf{1}$ & $\mathbf{2}$ & $\mathbf{3}$ & $\mathbf{4}$ & $\mathbf{5}$ & $\mathbf{6}$ & $\mathbf{7}$ & $\mathbf{8}$ & $\mathbf{9}$ & $\mathbf{1 0}$ & $\mathbf{1 1}$ & $\mathbf{1 2}$ & $\mathbf{1 3}$ \\
\hline 1 & 0 & 0 & 0 & 0 & 0 & 0 & 0 & 0 & 0 & 0 & 0 & 0 & 0 \\
\hline 2 & 0 & 0 & 0 & 0 & 1 & 1 & 1 & 1 & 1 & 1 & 1 & 1 & 1 \\
\hline 3 & 0 & 0 & 0 & 0 & 2 & 2 & 2 & 2 & 2 & 2 & 2 & 2 & 2 \\
\hline 4 & 0 & 1 & 1 & 1 & 0 & 0 & 0 & 1 & 1 & 1 & 2 & 2 & 2 \\
\hline 5 & 0 & 1 & 1 & 1 & 1 & 1 & 1 & 2 & 2 & 2 & 0 & 0 & 0 \\
\hline 6 & 0 & 1 & 1 & 1 & 2 & 2 & 2 & 0 & 0 & 0 & 1 & 1 & 1 \\
\hline 7 & 0 & 2 & 2 & 2 & 0 & 0 & 0 & 2 & 2 & 2 & 1 & 1 & 1 \\
\hline 8 & 0 & 2 & 2 & 2 & 1 & 1 & 1 & 0 & 0 & 0 & 2 & 2 & 2 \\
\hline 9 & 0 & 2 & 2 & 2 & 2 & 2 & 2 & 1 & 1 & 1 & 0 & 0 & 0 \\
\hline 10 & 1 & 0 & 1 & 2 & 0 & 1 & 2 & 0 & 1 & 2 & 0 & 1 & 2 \\
\hline 11 & 1 & 0 & 1 & 2 & 1 & 2 & 0 & 1 & 2 & 1 & 1 & 2 & 0 \\
\hline 12 & 1 & 0 & 1 & 2 & 2 & 0 & 1 & 2 & 0 & 0 & 2 & 0 & 1 \\
\hline 13 & 1 & 1 & 2 & 0 & 0 & 1 & 2 & 1 & 2 & 0 & 2 & 0 & 1 \\
\hline 14 & 1 & 1 & 2 & 0 & 1 & 2 & 0 & 2 & 0 & 1 & 0 & 1 & 2 \\
\hline 15 & 1 & 1 & 2 & 0 & 2 & 0 & 1 & 0 & 1 & 2 & 1 & 2 & 0 \\
\hline 16 & 1 & 2 & 0 & 1 & 0 & 1 & 2 & 2 & 0 & 1 & 1 & 2 & 0 \\
\hline 17 & 1 & 2 & 0 & 1 & 1 & 2 & 0 & 0 & 1 & 2 & 2 & 0 & 1 \\
\hline 18 & 1 & 2 & 0 & 1 & 2 & 0 & 1 & 1 & 2 & 0 & 0 & 1 & 2 \\
\hline 19 & 2 & 0 & 2 & 0 & 0 & 2 & 1 & 0 & 2 & 1 & 0 & 2 & 1 \\
\hline 20 & 2 & 0 & 2 & 0 & 1 & 0 & 2 & 1 & 0 & 2 & 1 & 0 & 2 \\
\hline 21 & 2 & 0 & 2 & 0 & 2 & 1 & 0 & 2 & 1 & 0 & 2 & 1 & 0 \\
\hline 22 & 2 & 1 & 0 & 1 & 0 & 2 & 1 & 1 & 0 & 2 & 2 & 1 & 0 \\
\hline 23 & 2 & 1 & 0 & 1 & 1 & 0 & 2 & 2 & 1 & 0 & 0 & 2 & 1 \\
\hline 24 & 2 & 1 & 0 & 1 & 2 & 1 & 0 & 1 & 2 & 1 & 1 & 0 & 2 \\
\hline 25 & 2 & 2 & 1 & 2 & 0 & 2 & 1 & 2 & 1 & 0 & 1 & 0 & 2 \\
\hline 26 & 2 & 2 & 1 & 2 & 1 & 0 & 2 & 0 & 2 & 1 & 2 & 1 & 0 \\
\hline 27 & 2 & 2 & 1 & 2 & 2 & 1 & 0 & 1 & 0 & 2 & 0 & 2 & 1 \\
\hline
\end{tabular}

Pareto ANOVA is one of the techniques to analyze the data for the optimization. It is a simplified ANOVA method which uses Pareto principles. It is a quick and easy method to analyze the results of parameter design. The Pareto ANOVA technique of analysis has been performed, which requires least knowledge about ANOVA method and suitable for engineers. The Table 6 shows the Pareto ANOVA analysis for MRR. From the Pareto ANOVA method, the results of shows that the capacitance (Factor B) and interaction AXC have strong influence on the MRR. Based on the result it is concluded that, the maximum MRR was 
obtained at high value of capacitance, medium value of feed rate and high value of voltage. That is the optimal combination to get the maximum value of MRR is $\mathrm{A}_{1} \mathrm{~B}_{2} \mathrm{C}_{2}$ within the tested range of experiment.

Based on the above two techniques of data analysis draw similar conclusions. The most significant factor for producing the maximum MRR is high value of capacitance, medium value of feed rate and high value of voltage. It is concluded that use of high value of capacitance, medium value of feed rate and high value of voltage are recommended to obtain the maximum MRR in micro-WEDG process. The optimized parameters in micro-WEDG process for the maximum MRR are determines as feed rate $=$ $4 \mu \mathrm{m} / \mathrm{sec}$, capacitance $=10.0 \mathrm{nF}$ and Voltage $=120 \mathrm{~V}$ within the tested range of experiment. The optimized machining parameters were used for the confirmation of experiments for validation; the measured value for the MRR is $0.39 \mu \mathrm{m}$.

Table 3. Experimental design, measured responses and their corresponding $\mathrm{S} / \mathrm{N}$ ratio

\begin{tabular}{|c|c|c|c|c|c|c|}
\hline \multirow{2}{*}{ Exp.No } & \multicolumn{3}{|c|}{ Factor } & & \multicolumn{2}{c|}{$\begin{array}{c}\text { Measured responses and their } \\
\text { corresponding S/N ratio }\end{array}$} \\
\cline { 2 - 3 } & $\mathbf{A}$ & $\mathbf{B}$ & $\mathbf{C}$ & & & $\begin{array}{c}\text { Designation } \\
\text { MRatio for } \\
\text { MRR(db) }\end{array}$ \\
\hline 1 & 0 & 0 & 0 & $\mathrm{~A}_{0} \mathrm{~B}_{0} \mathrm{C}_{0}$ & 0.02 & -3.398 \\
\hline 2 & 0 & 1 & 1 & $\mathrm{~A}_{0} \mathrm{~B}_{1} \mathrm{C}_{1}$ & 0.06 & -2.444 \\
\hline 3 & 0 & 2 & 2 & $\mathrm{~A}_{0} \mathrm{~B}_{2} \mathrm{C}_{2}$ & 0.15 & -1.648 \\
\hline 4 & 1 & 0 & 0 & $\mathrm{~A}_{1} \mathrm{~B}_{0} \mathrm{C}_{0}$ & 0.05 & -2.602 \\
\hline 5 & 1 & 1 & 1 & $\mathrm{~A}_{1} \mathrm{~B}_{1} \mathrm{C}_{1}$ & 0.14 & -1.708 \\
\hline 6 & 1 & 2 & 2 & $\mathrm{~A}_{1} \mathrm{~B}_{2} \mathrm{C}_{2}$ & 0.39 & -0.818 \\
\hline 7 & 2 & 0 & 0 & $\mathrm{~A}_{2} \mathrm{~B}_{0} \mathrm{C}_{0}$ & 0.05 & -2.602 \\
\hline 8 & 2 & 1 & 1 & $\mathrm{~A}_{2} \mathrm{~B}_{1} \mathrm{C}_{1}$ & 0.13 & -1.772 \\
\hline 9 & 2 & 2 & 2 & $\mathrm{~A}_{2} \mathrm{~B}_{2} \mathrm{C}_{2}$ & 0.14 & -1.708 \\
\hline 10 & 0 & 0 & 1 & $\mathrm{~A}_{0} \mathrm{~B}_{0} \mathrm{C}_{1}$ & 0.03 & -3.046 \\
\hline 11 & 0 & 1 & 2 & $\mathrm{~A}_{0} \mathrm{~B}_{1} \mathrm{C}_{2}$ & 0.07 & -2.310 \\
\hline 12 & 0 & 2 & 0 & $\mathrm{~A}_{0} \mathrm{~B}_{2} \mathrm{C}_{0}$ & 0.06 & -2.444 \\
\hline 13 & 1 & 0 & 1 & $\mathrm{~A}_{1} \mathrm{~B}_{0} \mathrm{C}_{1}$ & 0.07 & -2.310 \\
\hline 14 & 1 & 1 & 2 & $\mathrm{~A}_{1} \mathrm{~B}_{1} \mathrm{C}_{2}$ & 0.32 & -0.990 \\
\hline 15 & 1 & 2 & 0 & $\mathrm{~A}_{1} \mathrm{~B}_{2} \mathrm{C}_{0}$ & 0.09 & -2.092 \\
\hline 16 & 2 & 0 & 1 & $\mathrm{~A}_{2} \mathrm{~B}_{0} \mathrm{C}_{1}$ & 0.08 & -2.194 \\
\hline 17 & 2 & 1 & 2 & $\mathrm{~A}_{2} \mathrm{~B}_{1} \mathrm{C}_{2}$ & 0.14 & -1.708 \\
\hline 18 & 2 & 2 & 0 & $\mathrm{~A}_{2} \mathrm{~B}_{2} \mathrm{C}_{0}$ & 0.11 & -1.917 \\
\hline 19 & 0 & 0 & 2 & $\mathrm{~A}_{0} \mathrm{~B}_{0} \mathrm{C}_{2}$ & 0.06 & -2.444 \\
\hline 20 & 0 & 1 & 0 & $\mathrm{~A}_{0} \mathrm{~B}_{1} \mathrm{C}_{0}$ & 0.03 & -3.046 \\
\hline 21 & 0 & 2 & 1 & $\mathrm{~A}_{0} \mathrm{~B}_{2} \mathrm{C}_{1}$ & 0.10 & -2.000 \\
\hline 22 & 1 & 0 & 2 & $\mathrm{~A}_{1} \mathrm{~B}_{0} \mathrm{C}_{2}$ & 0.12 & -1.842 \\
\hline 23 & 1 & 1 & 0 & $\mathrm{~A}_{1} \mathrm{~B}_{1} \mathrm{C}_{0}$ & 0.06 & -2.444 \\
\hline 24 & 1 & 2 & 1 & $\mathrm{~A}_{1} \mathrm{~B}_{2} \mathrm{C}_{1}$ & 0.33 & -0.963 \\
\hline 25 & 2 & 0 & 2 & $\mathrm{~A}_{2} \mathrm{~B}_{0} \mathrm{C}_{2}$ & 0.10 & -2.000 \\
\hline 26 & 2 & 1 & 0 & $\mathrm{~A}_{2} \mathrm{~B}_{1} \mathrm{C}_{0}$ & 0.07 & -2.310 \\
\hline 27 & 2 & 2 & 1 & $\mathrm{~A}_{2} \mathrm{~B}_{2} \mathrm{C}_{1}$ & 0.13 & -1.772 \\
\hline
\end{tabular}

Table 4. Response table for Average $\mathrm{S} / \mathrm{N}$ ratio for MRR and significant interaction.

\begin{tabular}{|l|l|l|l|l|c|}
\hline Symbol & \multirow{2}{*}{ Cutting parameters } & \multicolumn{4}{|c|}{ Mean S/N ratio } \\
\cline { 3 - 6 } & & Level 0 & Level 1 & Level 2 & Max.- Min. \\
\hline A & Feedrate $(\mu \mathrm{m} / \mathrm{sec})$ & -2.531 & -1.752 & -1.998 & 0.779 \\
\hline B & Capacitance $(\mathrm{nF})$ & -2.493 & -2.081 & -1.707 & 0.786 \\
\hline C & Voltage $(V)$ & -2.54 & -2.023 & -1.719 & 0.821 \\
\hline AXC & Interaction $\mathrm{AXC}$ & -2.031 & -2.227 & -2.024 & 0.203 \\
\hline
\end{tabular}


Table 5. The calculated AC two-way table for MRR

\begin{tabular}{|c|l|l|l|c|}
\hline Factor & \multicolumn{1}{|c|}{$\mathbf{A}_{\mathbf{0}}$} & \multicolumn{1}{|c|}{$\mathbf{A}_{\mathbf{1}}$} & \multicolumn{1}{c|}{$\mathbf{A}_{\mathbf{2}}$} & Total \\
\hline $\mathbf{C}_{\mathbf{0}}$ & $-3.398-2.444-3.046=-8.888$ & $-2.602-2.092-2.444=-7.138$ & $-2.602-1.917-2.31=-6.829$ & -22.855 \\
\hline $\mathbf{C}_{\mathbf{1}}$ & $-2.444-3.046-2.0=-7.49$ & $-1.708-2.31-0.963=-4.981$ & $-1.772-2.194-1.772=-5.738$ & -18.209 \\
\hline $\mathbf{C}_{\mathbf{2}}$ & $-1.648-2.31-2.444=-6.402$ & $-0.818-0.99-1.842=-3.65$ & $-1.708-1.708-2.0=-5.416$ & -15.468 \\
\hline Total & -22.78 & -15.769 & -17.983 & -56.532 \\
\hline
\end{tabular}

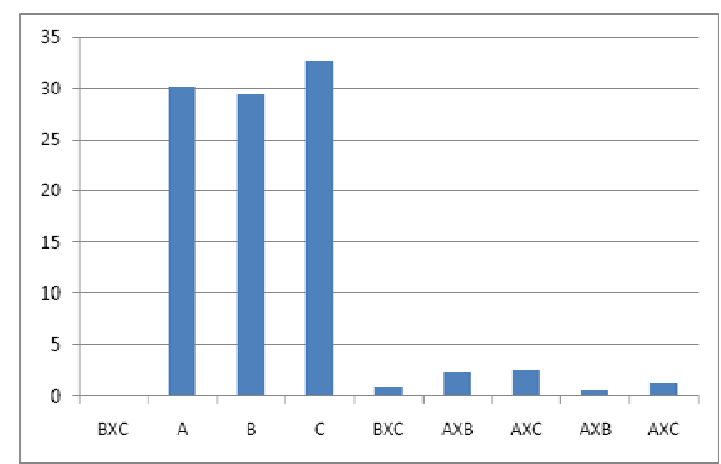

Figure 3. Pareto Diagram

(a)

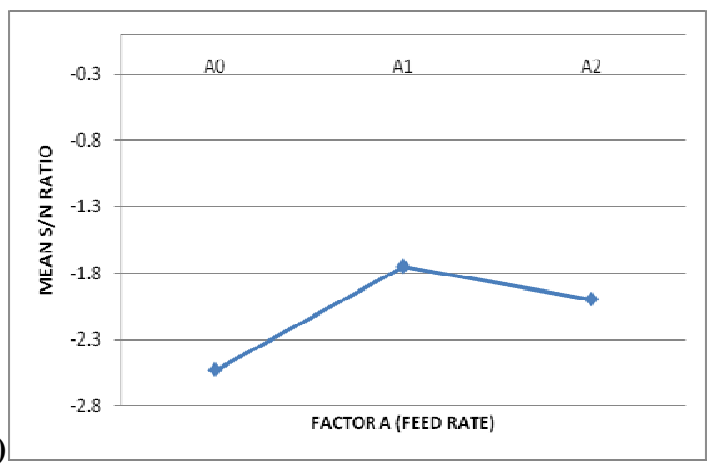

(b)

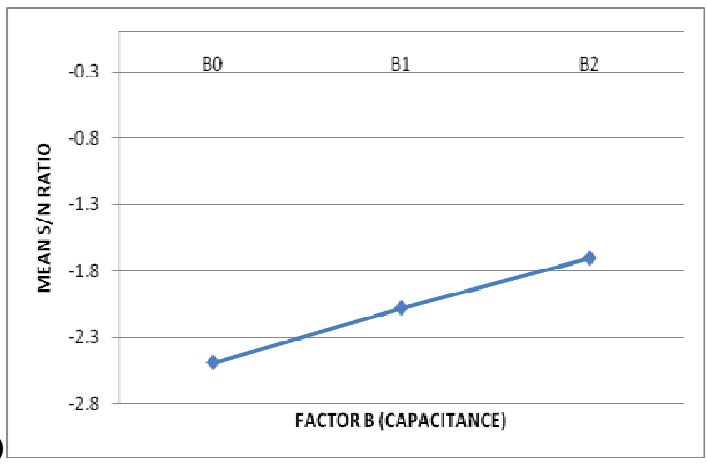

(c)

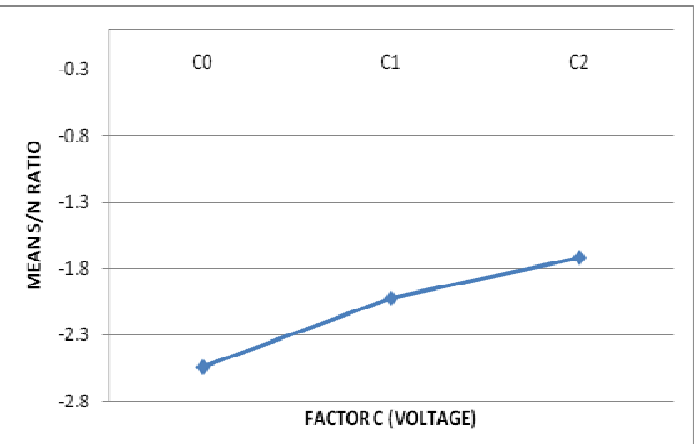


(d)

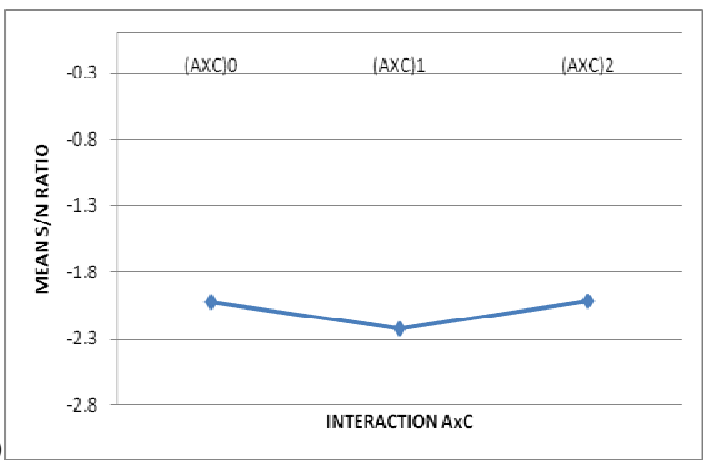

Figure 4. The Higher the better $\mathrm{S} / \mathrm{N}$ graph for Metal Removal Rate

Table 6. Pareto ANOVA analysis for MRR

\begin{tabular}{|c|c|c|c|c|c|c|c|c|c|}
\hline \multicolumn{10}{|c|}{ Factor and interaction } \\
\hline & B X C & $\mathbf{A}$ & $\mathbf{B}$ & C & B X C & A X B & A X C & A X B & A X C \\
\hline $\begin{array}{c}\text { Sum at } \\
\text { factor level }\end{array}$ & \multirow[t]{2}{*}{-18.7} & \multirow[t]{2}{*}{-22.78} & \multirow[t]{2}{*}{-22.438} & \multirow[t]{2}{*}{-22.855} & \multirow[t]{2}{*}{-18.345} & \multirow[t]{2}{*}{-18.551} & \multirow[t]{2}{*}{-18.276} & \multirow[t]{2}{*}{-19.427} & \multirow[t]{2}{*}{-19.285} \\
\hline $\mathbf{0}$ & & & & & & & & & \\
\hline 1 & -19.011 & -15.769 & -18.732 & -18.209 & -18.663 & -19.951 & -20.044 & -18.469 & -17.969 \\
\hline 2 & -18.821 & -17.983 & -15.362 & -15.468 & -19.524 & -18.03 & -18.212 & -18.636 & -19.278 \\
\hline $\begin{array}{l}\text { Sum of } \\
\text { squares of } \\
\text { difference } \\
\text { (S) }\end{array}$ & 0.3689 & 77.067 & 75.1611 & 83.6662 & 2.2325 & 5.9217 & 6.4861 & 1.5713 & 3.44540 \\
\hline $\begin{array}{l}\text { Contribution } \\
\text { ratio }(\%)\end{array}$ & $0.14 \%$ & $30.11 \%$ & $29.37 \%$ & $32.69 \%$ & $0.87 \%$ & $2.31 \%$ & $2.53 \%$ & $0.61 \%$ & $1.35 \%$ \\
\hline
\end{tabular}

Check on Significant interaction: AC two way Table: 5

Optimum combination of significant factor level: $\mathrm{A}_{1} \mathrm{~B}_{2} \mathrm{C}_{2}$

Table 7. Confirmation Experiment

\begin{tabular}{|l|c|c|c|}
\hline $\begin{array}{c}\text { Optimized parameter for the } \\
\text { micro-WEDG process }\end{array}$ & Using Taguchi technique & Using Pareto ANOVA & $\begin{array}{c}\text { Measured value of } \\
\text { Response }\end{array}$ \\
\cline { 1 - 3 } 1.Feed rate $\mu \mathrm{m} / \mathrm{sec}$ (FactorA) & $\mathrm{A}_{1}=4$ & $\mathrm{~A}_{1}=4$ & \multirow{2}{*}{ MRR $=0.39 \mathrm{mg} / \mathrm{min}$} \\
\cline { 1 - 3 } 2.Capacitance in $\mathrm{nF}$ (Factor $\mathrm{B})$ & $\mathrm{B}_{2}=10.0$ & $\mathrm{~B}_{2}=10.0$ & \\
\cline { 1 - 3 } 3.Volatge in $\mathrm{V}$ (Factor $\mathrm{C})$ & $\mathrm{C}_{2}=120$ & $\mathrm{C}_{2}=120$ & \\
\hline
\end{tabular}

\section{Conclusions}

In this study, the effects of the process parameters such as feed rate, capacitance and voltage on the MRR in the micro-WEDG were investigated. Based on this experimental work and analysis for the micro-WEDG process using Taguchi technique and Pareto ANOVA, the following results were obtained.

1. Taguchi's robust design of experiment technique is suitable to analyze the micro-WEDG problems. From this experimental work shows the optimal parameters for micro-WEDG process using Taguchi approach and Pareto ANOVA for data analysis draw same conclusion.

2. Based on the experimental result and the statistical analysis, it was concluded that feed rate, capacitance and voltage is more significant factor for MRR. Based on the Taguchi analysis and Pareto ANOVA analysis it is concluded that MRR increase with increase of feed rate, capacitance and voltage. At the same time the result shows that the individual effect of feed rate, capacitance and voltage are more contribution on MRR comparing to the interaction effect. Also from this experiment it is concluded that use of medium feed rate, higher value of capacitance and voltage are recommended to obtain the maximum MRR in micro-WEDG process. 
3. The optimum micro-WEDG process parameters for the maximum MRR are determines as feed rate $=4 \mu \mathrm{m} / \mathrm{sec}$, capacitance $=$ $10.0 \mathrm{nF}$ and Voltage $=120 \mathrm{~V}$ within the tested range of experiment. The optimized machining parameters were used for the confirmation of experiments for validation; the measured value for the MRR is $0.39 \mu \mathrm{m}$.

\section{Acknowledgements}

The authors are extremely thankful to the Joint Director Mr.P.V.Shasi Kumar, Scientist Mr.M.Chellamalai and Scientist Mr. S.Gopikrishna, Central Manufacturing Technology Institute, Bangalore for their valuable comments and suggestions which contributed significantly to improve the quality of this research work.

\section{References}

Bao W.Y., Tansel I.N. 2000, Modeling micro-end-milling operations. Part I: analytical cutting force model, Int. J. Machine tools Manuf. Vol.40, pp. 2155-2173.

Bao W.Y., Tansel I.N. 2000, Modeling micro-end-milling operations. Part II: tool run out, Int. J. Machine tools Manuf. Vol.40, pp. 2175-2192.

Bao W.Y., Tansel, I.N. 2000, Modeling micro-end-milling operations. Part III: influence of tool wear, Int. J. Machine tools Manuf. Vol.40, pp. 2193-2211

Bigot S., Valentincic J., Blatnik O., Junkar M. 2006, Micro-EDM parameters optimization, Second International Conference on Multi- material Micro manufacture, Grenoble, France, September, 20-22.

Bigot S, Ivanov A, Popov K, 2005. A study of the micro-EDM electrode wear. Proceedings of the First International Conference on Multi-Material Micro-Manufacture, 4M, pp $355-358$.

Bissacco G.. Valentincic J...Hansen H.N. Wiwe B.D. 2010, Towards the effective tool wear control in micro-EDM milling, Int J Adv Manuf. Technol, vol.47, pp.3-9.

Chris JM Vallance RR Marsh ER 2006, Micromachining and micro grinding with tools fabricated by micro-electro discharge machining, Int J. Nano-manufacturing, vol.1, pp.242-258.

Fujimasa I., Micro machines 1996: A new era in mechanical engineering, Oxford University Press.

Kunieda M., Lauwers B. , Rajurkar K.P., Schumacher B.M. 2006, Advancing EDM through fundamental insight into the process, Annals of the CIRP, vol.54, No.2, pp.599-622.

Lee K., Dornfeld D.A.. 2004, A study of surface roughness in the micro end milling process, Consortium on deburring and edge finishing, Laboratory for manufacturing and sustainability, UC Berkeley.

Lu Z., Yoneyama T.. 1999, Micro cutting in the micro lathe turning system, Int. J. Machine Tools Manuf. Vol.39, pp. 1171-1183.

Masuzawa.T, 2001, Micro-EDM, Proceedings of the $13^{\text {th }}$ International Symposium for Electromachining ISEM XIII, Vol. 1, pp. 319, May.

Masuzawa T., Fujino M., Kobayashi K. 1985, Wire electro-discharge grinding for micro-machining, Annals of the CIRP, vol.34, No.1, pp. 431-434.

Matsui S., Kaito T., Fujita J.I., Ishida M., Ochiai Y. 2001, Three dimensional nanostructure fabrication by focused-ion-beam chemical vapor deposition, J.Japan Soc. Precis. Eng,.Vol.67, No.9, pp.1412-1415.

Mehfuz R., Ali M.Y., 2008, Investigation of machining parameters for the multiple-response optimization of micro electro discharge milling. Int J Adv Manuf Technol, DOI: 10.1007/s00170-008-1705-0.

Natarajan U, Periyanan PR, Yang S.H. 2011,"Multiple-response optimization for micro-end milling process using response surface methodology", Int. J. Adv Manuf Technol, Vol. 56, pp.177-185.

Okuyama H., Takada H. 1998, Micromachining with SR and FEL, Nuclear Instrum. Methods Phys. Res. B 144, pp.58-65.

Park S.H. 1996, Robust Design and Analysis for Quality Engineering, Chapman \& Hall, London.

Periyanan PR, Natarajan U. 2011, Optimization of parameters in micro-WEDG process using Taguchi technique, National Conference on Emerging Approach for Sustainable Development (STEP MACC'2011) organized by Modular Based Credit Banking Scheme (MBCBS), Anna University of Technology, Tiruchirappalli, India, September 27, pp:39-40.

Periyanan P.R., Natarajan U., Yang S.H., 2011. A study on the machining parameters optimization of micro-end milling process, International Journal of Engineering, Science and Technology, Vol. 3, No. 6, pp. 237-246.

Phadke M.S. 1989, Quality Engineering Using Robust Design, Prentice-Hall, Englewood Cliffs, NJ.

Piltz S. Roehner M Uhlmann E. 2006, Manufacturing of micro cylindrical parts by electrical discharge machining processes. Proceedings of the $1^{\text {st }}$ International conference on micro-manufacturing ICOMM, pp. 265-269.

Popov K., Dimov S., Ivanov A., Pham D.T, Gandarias E. 2010, New tool-work piece setting up technology for micro-milling, Int J Adv Manuf Technol, vol.47, pp.21-27.

Prakash J.R.S., Senthil kumar A., Rahman M., Lim S.C. 2001, A model for predicting tool life for coated micro end mill, Proc. Fourth International Machining and Grinding Troy, Michigan 7-10 May, pp. 149-158.

Qu J Shih AJ Scattergood RO. 2002, Development of the cylindrical wire discharge machining process. Part1: Concept, design and material removal rate. Trans. Of the ASME 124, pp.702-707. 
Qu J Shih AJ Scattergood RO. 2002, Development of the cylindrical wire discharge machining process. Part2: Concept, surface integrity and roundness.. Trans. Of the ASME 124, pp. 708-714.

Rahman M, Kumar S., Prakash J.R.S. 2001, 'Micro milling of pure copper, J. Mater. Process. Technol., Vol.116, pp. 39-43.

Rahman M, Lim H.S., Neo, K.S. Senthilkumar A. Wong Y.S., Li, X.P., 2007, Tool based nanofinishing and micromachining, J. Mater. Process. Technol., Vol.185, pp.2-16.

Son S.M, Lim H.S., Ahn J.H. 2005, Effects of the friction co-efficient on the minimum cutting thickness in micro cutting, Int. J. Machine tools Manuf. Vol.45, pp. 529-535.

To S., Lee W.B., Chan C.Y. 1997, Ultra-precision diamond turning of aluminium single crystals, J. Mater. Process. Technol.., Vol.63, pp.157-162.

Unal R, Dean E.B. 1991, Taguchi approach to design optimization for quality and cost: an overview, in: Proceedings of the International Society of Parametric Analyst 13th Annual, May 21-24.

Jain V., Sharma A.K.and Kumar P., 2011, Recent developments and research issues in micro-machining, International Scholarly Research Network- ISRN Mechanical Engineering, doi:10.5402/2011/413231, pp. 1-15.

Wang W., Kweon S.H., Yang. S.H. 2005, A study on rougness of the micro end milled surface produced by a miniature machine tool, J. Mater. Process. Technol., Vol.162-163, pp. 702-708.

Weinert K., Petzoldt V. 2004, Machining of NiTi based shape memory alloy, Materials Science Engineering, A 378, pp.180-184.

Wong Y.S., Rahman M., Lim H.S., Han H. Ravi N. 2003, Investigation of micro-EDM material removal characteristics using single RC-pulse discharges, J. Mater. Process. Technol., Vol.140, No.1-3, pp. 303-307.

Yu Z.Y., Masuzawa T. Fujino M. 1998, Micro-EDM for three dimensional cavities - Development of uniform wear method, Annals of the CIRP. Vol.47, No.1.

\section{Biographical notes}

Mr. PR. Periyanan is an Asst. Professor in Mechanical Engineering Department, Shanmuganathan Engineering College, India. He obtained M.E in Manufacturing Engineering from Anna University Chennai, India. He has more than 10 years of experience in Teaching and Industrial field. He has published many research papers in National and International journals.

Dr. U. Natarajan is an Asst. Professor in Mechanical Engineering Department, A.C.College of Engineering and Technology, India. He got his ME in Manufacturing Engineering from NIT Tiruchirappalli, India, Ph.D.from Anna University Chennai, India and PDF from Kyungpook National University, Daegu, South Korea, He has more than 20 years of experience in Teaching and Industrial field He has published more than 50 research papers in National and International journals.

Dr. A. Elango is Professor in Mechanical Engineering Department, A.C.College of Engineering and Technology, India. He got his ME in Production Engineering from GCT Coimbatore, India, PhD from Anna University Chennai, India; He has more than 30 years of experience in Teaching and Industrial field. He has published many research papers in National and International journals.

Received October 2011

Accepted April 2012

Final acceptance in revised form August 2012 